Supporting Information for:

\title{
Size Control and Fractionation of Ionic-Liquid-Filled Polymersomes with Glassy and Rubbery Bilayer Membranes
}

\author{
Soonyong So ${ }^{\dagger}$ and Timothy P. Lodge ${ }^{*, \dagger, *}$ \\ Department of Chemical Engineering \& Materials Science ${ }^{\dagger}$ and Department of Chemistry, ${ }^{*}$ \\ University of Minnesota, Minneapolis, Minnesota 55455, United States
}
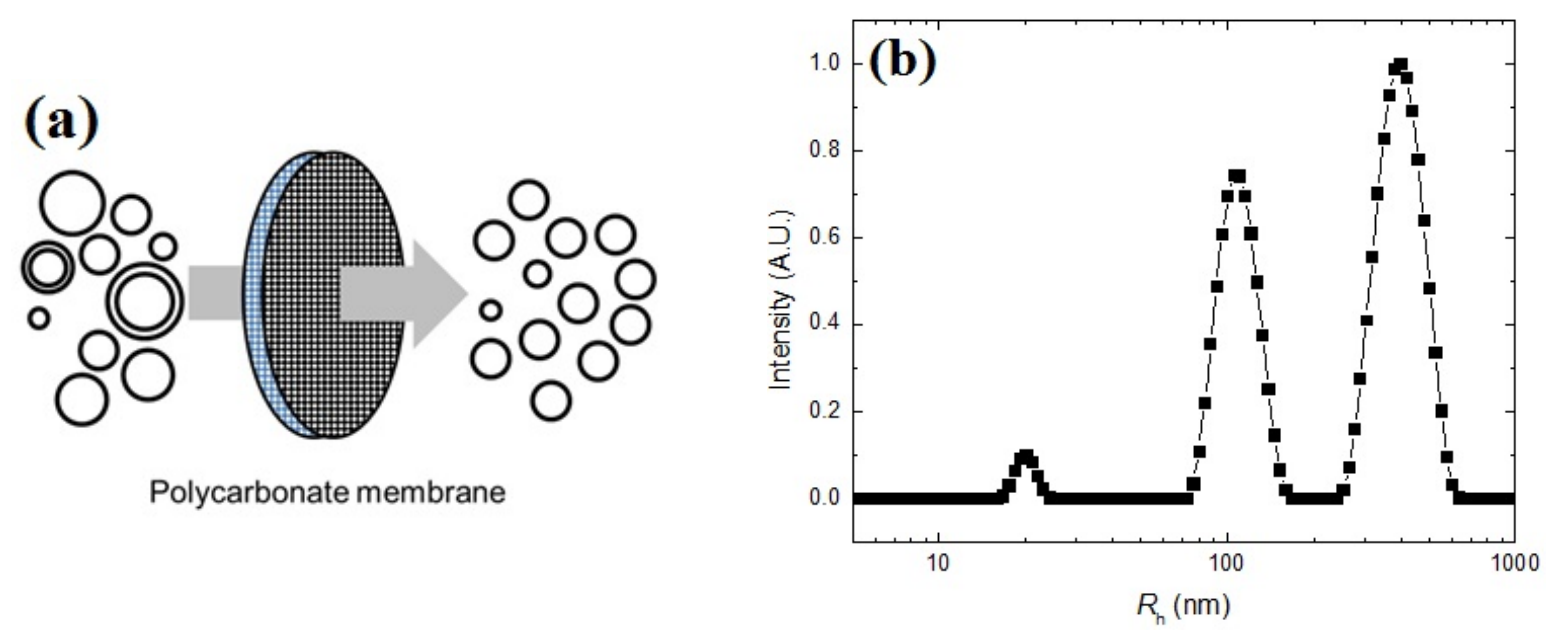

Figure S1. (a) Schematic description of polymersome extrusion through the membrane, and (b) Size distribution of $\mathrm{BO}(9-2.5)$ polymersomes in [EMIM][TFSI] prepared by the $\mathrm{TF}$ method. 


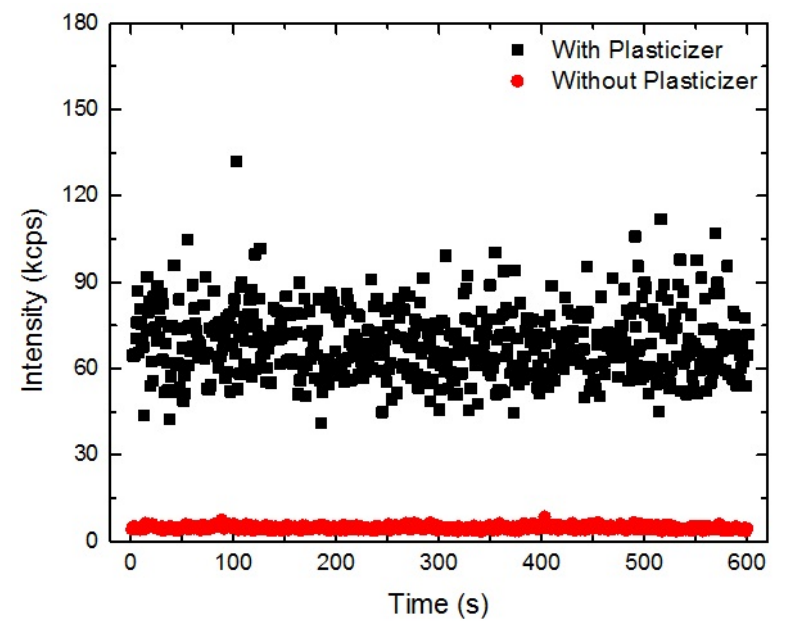

Figure S2. Scattering intensity comparison of the extruded suspension of SO(14-2.5) with 10 vol \% of DCM as plasticizer ( $\bullet$ ) and without plasticizer (•).
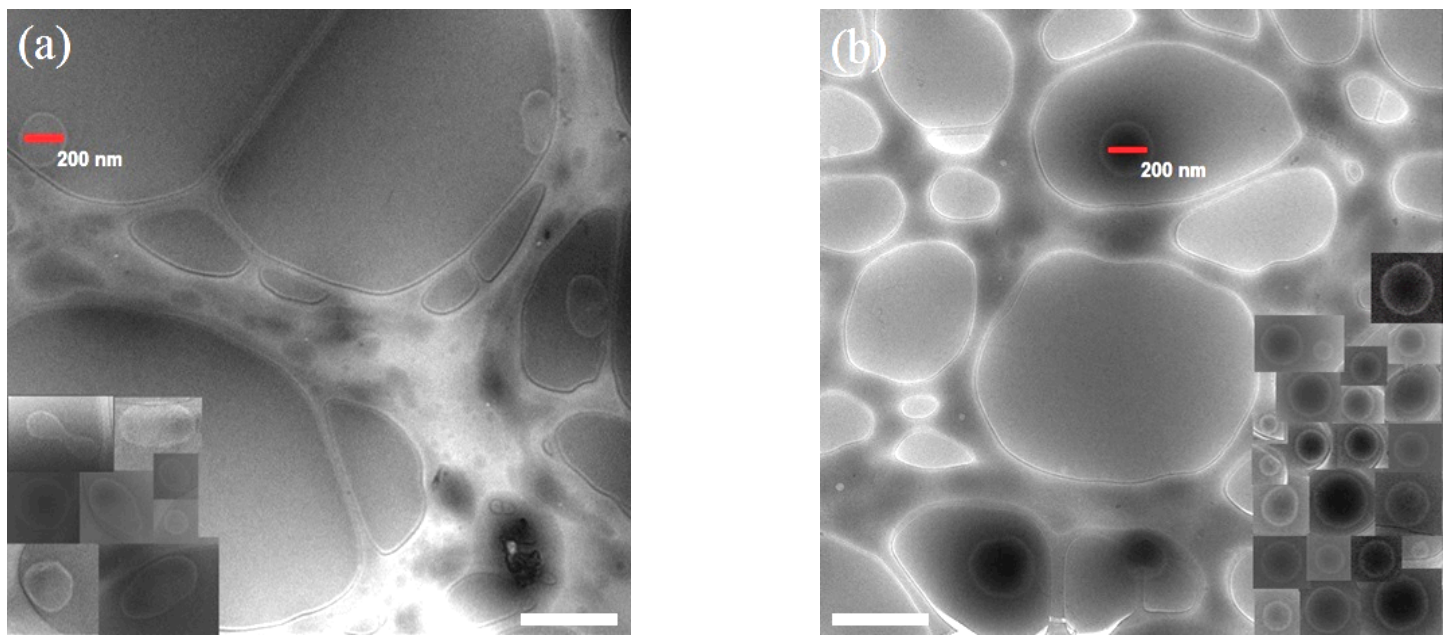

Figure S3. Cryo-TEM images of (a) SO(14-2.5) polymersomes in [EMIM][TFSI] after 9 extrusion passes with 10 vol \% of DCM, and (b) the polymersomes after being annealed at 100 ${ }^{\circ} \mathrm{C}$ after extrusion. Images of $\mathrm{SO}(14-2.5)$ polymersomes were collected and pasted on the image with the same scale. Scale bars: $500 \mathrm{~nm}$. 

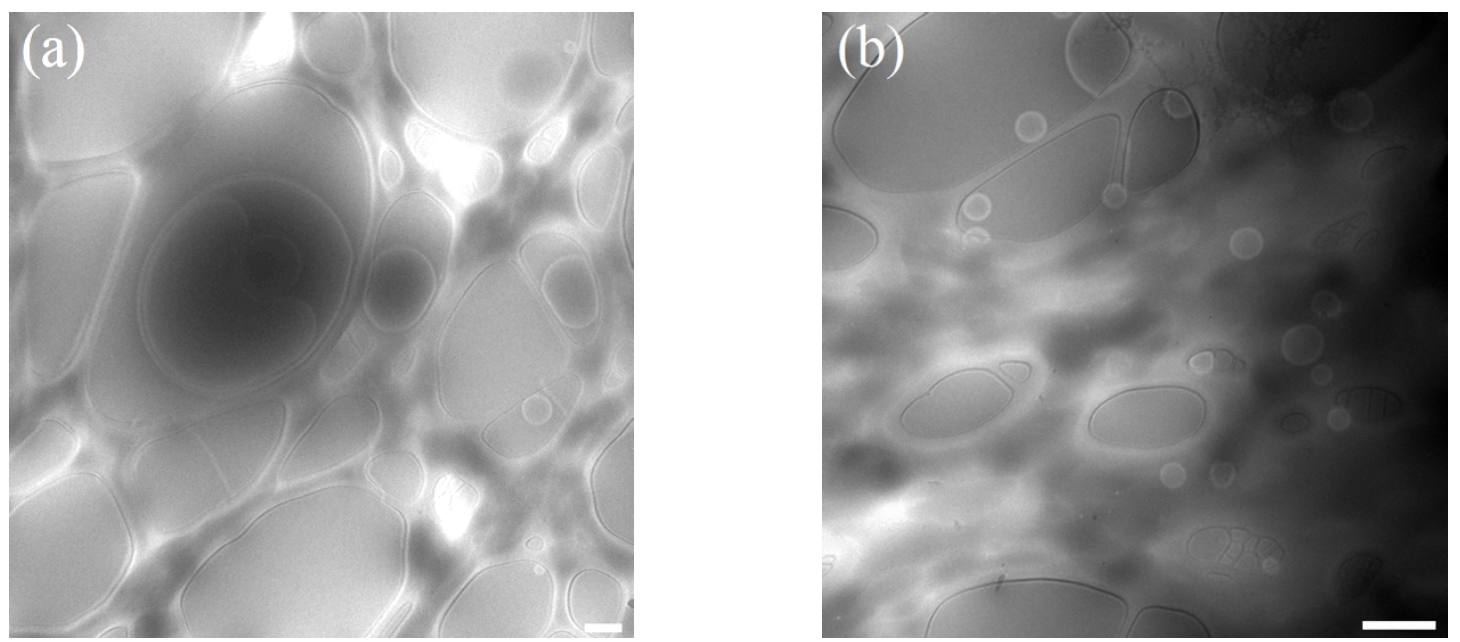

Figure S4. Cryo-TEM images of $\mathrm{BO}(9-2.5)$ polymersomes in [EMIM] [TFSI] (0.5 wt \%); (a) BO(9-2.5)-30, (b) BO(9-2.5)-60. Scale bars: $200 \mathrm{~nm}$.
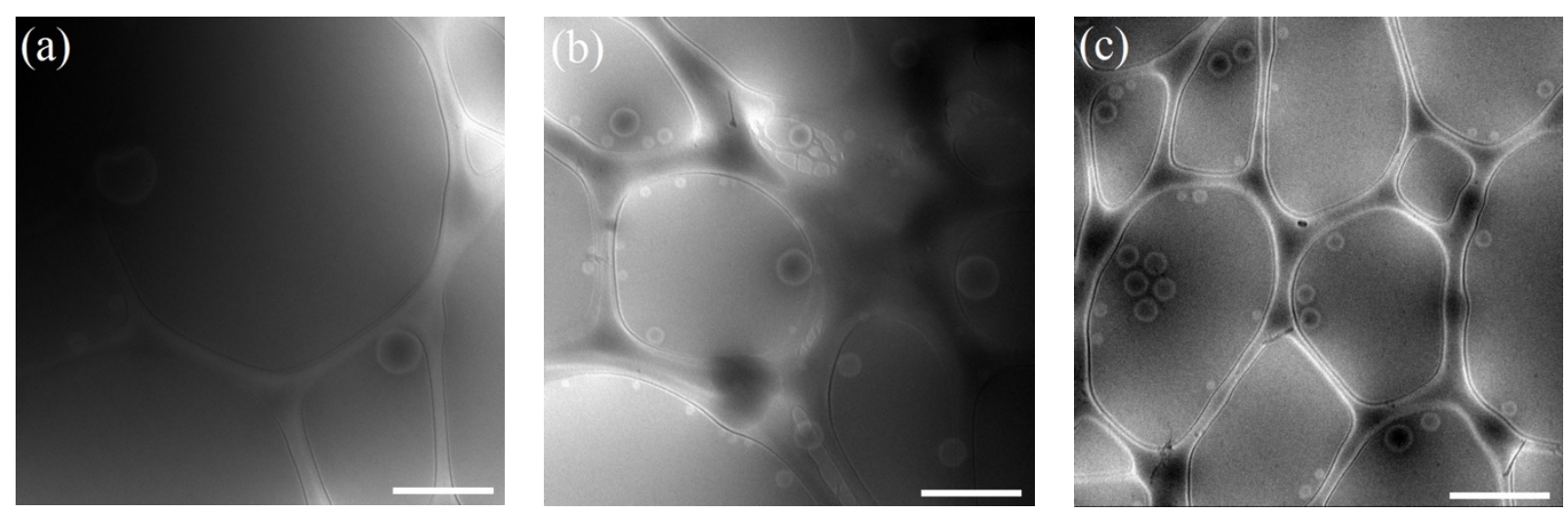

Figure S5. Cryo-TEM images of PS-PEO polymersomes having $18 \mathrm{~kg} / \mathrm{mol}$ of PS block, but different length of PEO in [EMIM][TFSI] (0.5 wt \%); (a) $\mathrm{SO}(18-2.5)$, (b) $\mathrm{SO}(18-3)$, (c) SO(18-3.6) with $60 \mathrm{vol} \%$ of initial DCM. Scale bars: $500 \mathrm{~nm}$. 

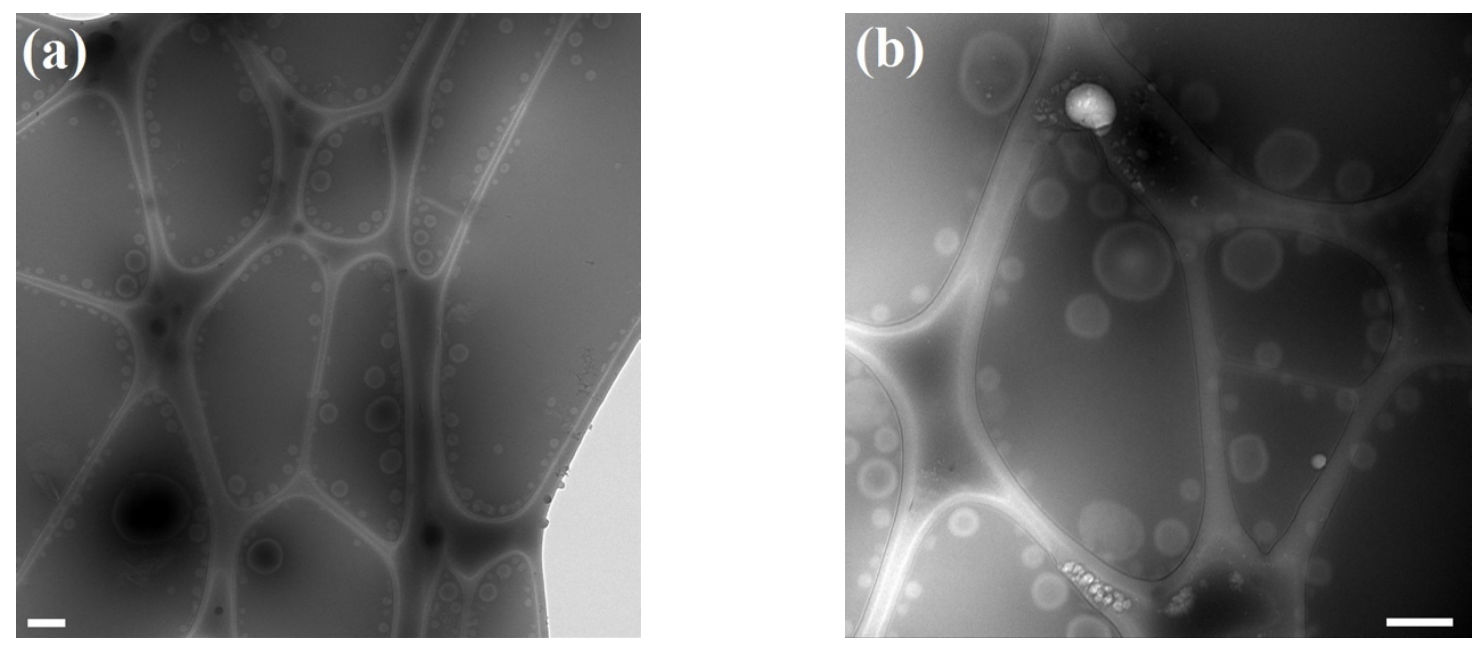

Figure S6. Cryo-TEM images of SO(18-3.6) polymersomes in [EMIM][TFSI] before contacting the aqueous phase. Scale bars: $200 \mathrm{~nm}$.

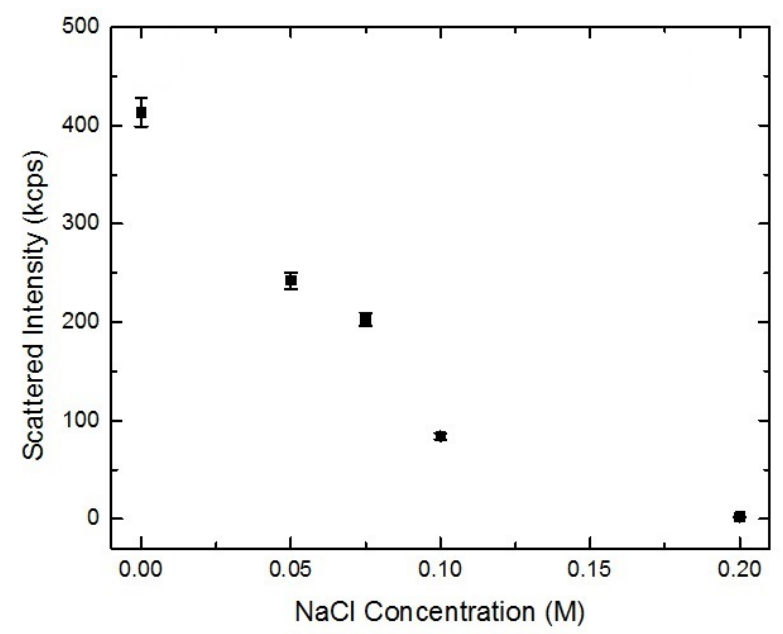

Figure S7. Scattered intensity of the upper phase after diluted to $0.01 \mathrm{wt}$. \% at different $\mathrm{NaCl}$ concentrations, using a $20 \mathrm{~mW} 637 \mathrm{~nm}$ He-Ne laser at $90^{\circ}$. 

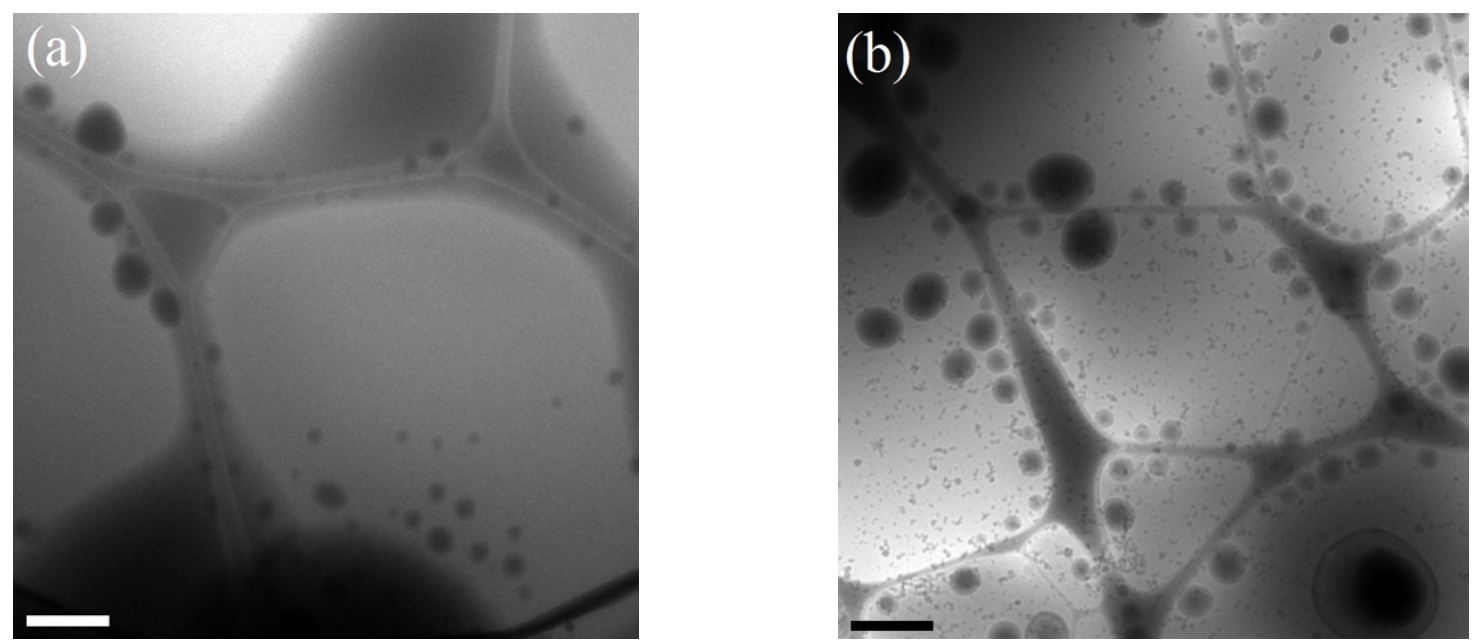

Figure S8. Cryo-TEM images of $\mathrm{SO}(18-3.6)$ polymersomes in the aqueous phase of (a) $0 \mathrm{M}$ $\mathrm{NaCl}$, and (b) $0.1 \mathrm{M} \mathrm{NaCl}$, respectively, from the IL phase by the transfer. Dark dots in (b) are from ethane contamination. Scale bars: $500 \mathrm{~nm}$.

Reduced Covering Density. The degree of the coverage can be quantified by the reduced tethering density $\left(\sigma_{\mathrm{PEO}}\right)$ which is defined as ${ }^{1,2}$

$$
\sigma_{\mathrm{PEO}}=\pi R_{\mathrm{g}, \mathrm{PEO}}{ }^{2} / S
$$

where $R_{\mathrm{g}, \mathrm{PEO}}$ is the radius of gyration of the PEO single chain calculated by $R_{\mathrm{g}}{ }^{2}=N b^{2} / 6$ for Gaussian coils ( $N$ is degree of polymerization, and $b$ is the statistical segment length of PEO, 6.0 $\AA)^{3}$, and $S$ is the unit area per PS chain on the PS core or membrane, calculated by

$$
S=A / N_{\text {agg }}
$$

where $A$ is the total surface area of PS core or membrane and $N_{\text {agg }}$ is the aggregation number. Depending on geometry, $A$ can be determined and described by following equations 


$$
\begin{gathered}
A_{\text {spherical }}=4 \pi R_{\mathrm{c}}{ }^{2}, \\
A_{\text {worm-like }}=2 \pi R_{\mathrm{c}} L,
\end{gathered}
$$

and

$$
A_{\text {polymersome }}=8 \pi R^{2},
$$

where $R_{\mathrm{c}}$ is the core dimension radius for worm-like and spherical micelles, $R$ in eqn $\mathrm{S} 3 \mathrm{c}$ is the radius of polymersomes excluding outer corona length. $L$ in eqn $\mathrm{S} 3 \mathrm{~b}$ is the length of worm-like micelles. $N_{\text {agg }}$ can be calculated from the equation, ${ }^{4}$

$$
N_{\mathrm{agg}}=\frac{V_{c} \rho_{\mathrm{PS}} N_{\mathrm{A}}}{M_{\mathrm{n}, \mathrm{PS}}},
$$

where $V_{\mathrm{c}}$ is volume of polymersome membrane or micelle core, $N_{\mathrm{A}}$ is Avogadro's number, and $M_{\mathrm{n}, \mathrm{PS}}$ is the number averaged molecular weight of PS block. The density of PS membrane is assumed to be $\rho_{\mathrm{PS}}=1.05 \mathrm{~g} / \mathrm{cm}^{3}$, the same as the bulk density of PS. ${ }^{5}$
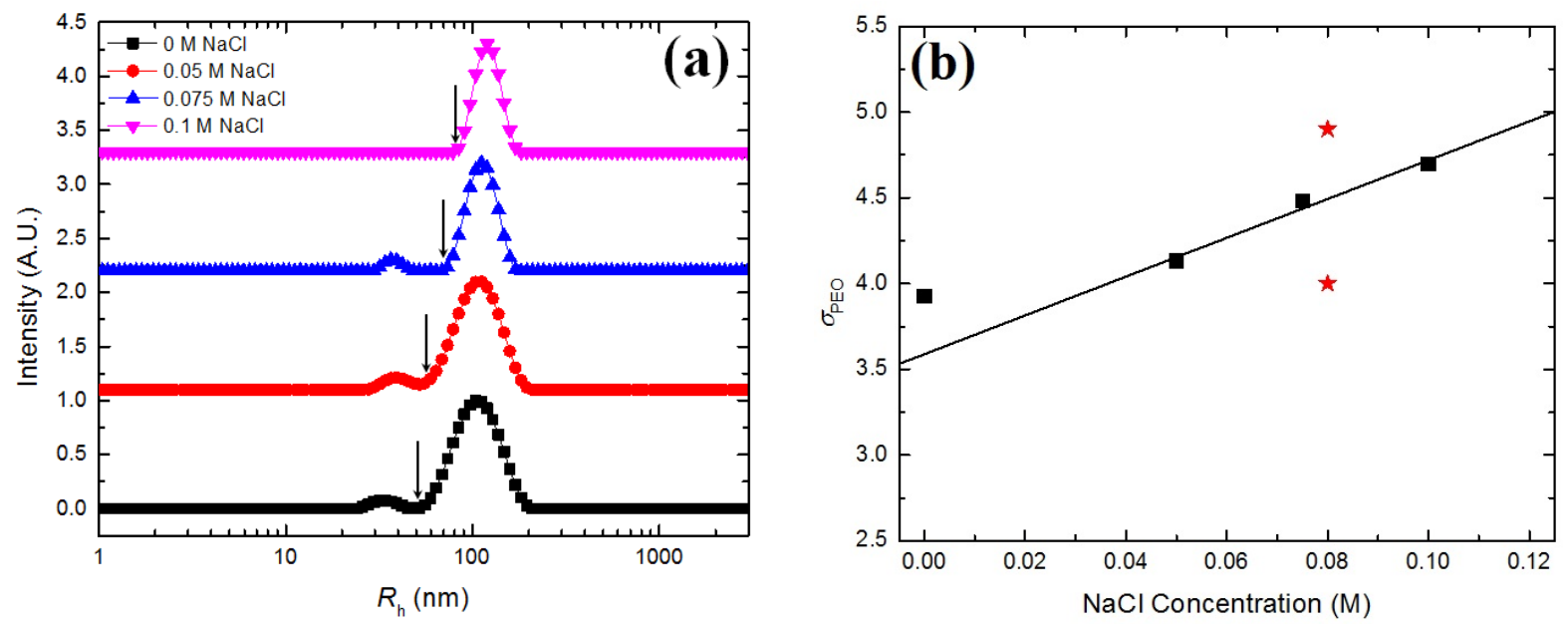

Figure S9. (a) Size distribution of $\mathrm{SO}(18-3.6)$ assemblies in the aqueous phase measured by DLS, and (b) Reduced tethering density ( $\left.\sigma_{\mathrm{PEO}}\right)$ with the cut-off size at various $\mathrm{NaCl}$ concentration from $0 \mathrm{M}$ to $0.1 \mathrm{M}$. The line is a proposed boundary line for the phase transfer, and the values ( $\star$ ) represents $\sigma_{\mathrm{PEO}}$ of the polymersomes (4.9) and the worm-like micelles (4.0) of $\mathrm{SO}(10-3)$. 
Boundary Line for Phase Transfer. New $\sigma_{\mathrm{PEO}, \mathrm{c}}$ values at different salt concentrations were estimated based on the size distribution from the DLS measurements (Figure S9a). The minimum size from the main peaks, which can be considered as a cut-off size of the polymersomes, was selected at each concentration in Figure S9a, and the corresponding $\sigma_{\mathrm{PEO}}$ values were calculated using eqn S1. As expected from the thermodynamic analysis, the calculated $\sigma_{\mathrm{PEO}}(\mathbf{\square})$ at the minimum size increased with the concentration of $\mathrm{NaCl}$ from 3.9 to 4.7. Especially, the values within the range from $0.05 \mathrm{M}$ to $0.1 \mathrm{M} \mathrm{NaCl}$ fall on a single straight line as shown in Figure $\mathrm{S} 9 \mathrm{~b}$, but the value at $0 \mathrm{M} \mathrm{NaCl}$ is off from the straight line. This trend is reasonable because only $\sigma_{\mathrm{PEO}, \mathrm{c}}$ in pure water is well below the $\sigma_{\mathrm{PEO}}$ values of all polymersomes, whereas others at higher $\mathrm{NaCl}$ content are in the range of the polymersome $\sigma_{\mathrm{PEO}}$ values. Therefore, $\sigma_{\mathrm{PEO}}$ values above 0.05 $\mathrm{M} \mathrm{NaCl}$ with the minimum size of the polymersomes can be considered as new $\sigma_{\mathrm{PEO}, \mathrm{c}}$ values, and the straight line can be considered as a phase transfer boundary as a function of the concentration of $\mathrm{NaCl}$. Interestingly, the intercept of the boundary line is around 3.6 corresponding to the value reported before in pure water, ${ }^{1,6}$ so it is a plausible method to estimate $\sigma_{\mathrm{PEO}, \mathrm{c}}$.
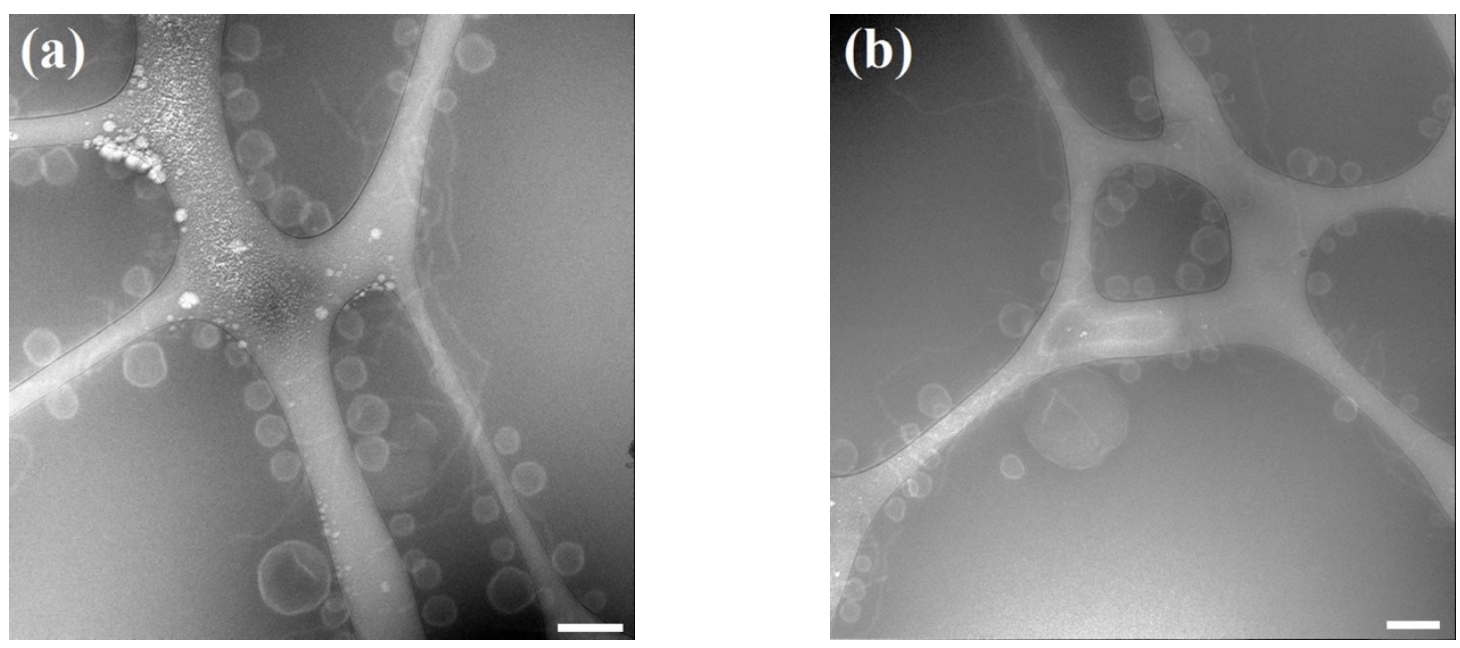

Figure S10. Cryo-TEM images of $\mathrm{SO}(10-3)$ polymersomes and worm-like micelles in [EMIM][TFSI] before contacting the aqueous phase. Scale bars: $200 \mathrm{~nm}$. 
Salt Concentration for Fractionation Depending on Morphology. With the dimensional information from the TEM images (Figure 11a), we calculated that $\sigma_{\mathrm{PEO}}$ of the polymersomes $(<R>\approx 51 \mathrm{~nm})$ is around 4.9 , whereas the calculated $\sigma_{\mathrm{PEO}}$ of the worm-like micelles is around 4.0. To have selective phase transfer of the polymersomes, $\sigma_{\mathrm{PEO}, \mathrm{c}}$ was set around 4.5 , which is between the $\sigma_{\mathrm{PEO}}$ values of the polymersomes and the worm-like micelles, by varying the $\mathrm{NaCl}$ content to $0.08 \mathrm{M} \mathrm{NaCl}$ (see the values $(\star)$ of worm-like micelle and polymersomes in Figure $\mathrm{S} 9 \mathrm{~b})$. Some polymersomes can also be found, but they have relatively smaller size $(<R>=38$ $\left.\mathrm{nm}, \sigma_{\mathrm{PEO}} \sim 4.5\right)$, which were rejected by the shifted $\sigma_{\mathrm{PEO}, \mathrm{c}}$, compared to the transferred polymersomes $\left(<R>=57 \mathrm{~nm}, \sigma_{\mathrm{PEO}} \sim 5.1\right)$. Thus, the worm-like micelles could not transfer to the aqueous phase and remained in the IL phase due to the shifted $\sigma_{\mathrm{PEO}, \mathrm{c}}$, while polymersomes having higher $\sigma_{\mathrm{PEO}}$ than the new $\sigma_{\mathrm{PEO}, \mathrm{c}} \sim 4.5$ could transfer to the aqueous phase. Therefore, the phase transfer boundary obtained from SO(18-3.6) polymersome case was successfully applied to a different system having different molecular weight and morphologies.

\section{O M $\quad 0.08 \mathrm{M}$}

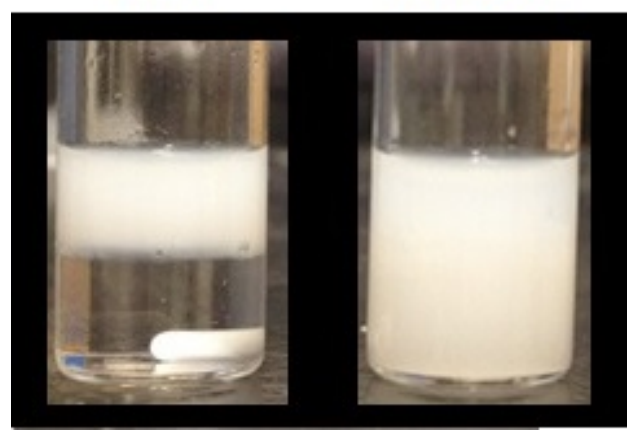

Figure S11. Images of $\mathrm{SO}(10-3)$ polymersomes in [EMIM][TFSI] (bottom phase) and aqueous $\mathrm{NaCl}$ solution (upper phase) biphasic system. The concentration of $\mathrm{NaCl}$ in the upper phase was varied from $0 \mathrm{M}$ to $0.08 \mathrm{M}$. 


\section{REFERENCES}

(1) Chen, W. Y.; Zheng, J. X.; Cheng, S. Z. D.; Li, C. Y.; Huang, P.; Zhu, L.; Xiong, H.; Ge, Q.; Guo, Y.; Quirk, R. P.; Lotz. B.; Deng, L.; Wu, C.; Thomas, E. L. Onset of Tethered Chain Overcrowding. Phys. Rev. Lett. 2004, 93, 028301.

(2) Sanada, Y.; Akiba, I.; Sakurai, K.; Shiraishi, K.; Yokoyama, M.; Mylonas, E.; Ohta, N.; Yagi, N.; Shinohara, Y.; Amemiya, Y. Hydrophobic Molecules Infiltrating into the Poly(ethylene glycol) Domain of the Core/Shell Interface of a Polymeric Micelle: Evidence Obtained with Anomalous Small-Angle X - Ray Scattering. J. Am. Chem. Soc. 2013, 135, 2574-2582.

(3) Hiemenz, P. C.; Lodge, T. P. Polymer Chemistry, 2nd ed; CRC Press: Boca Raton, London, New York, 2007

(4) He, Y.; Li, Z.; Simone, P.; Lodge, T. P. Self-Assembly of Block Copolymer Micelles in an Ionic Liquid. J. Am. Chem. Soc. 2006, 128, 2745-2750.

(5) Simone, P. M.; Lodge, T. P. Micellization of PS-PMMA Diblock Copolymers in an Ionic Liquid. Macromol. Chem. Phys. 2007, 208, 339-348.

(6) So, S.; Lodge, T. P. Interfacial Tension-Hindered Phase Transfer of Polystyrene- $b$ Poly(ethylene oxide) Polymersomes from a Hydrophobic Ionic Liquid to Water. Langmuir 2015, 31, 594-601. 